\title{
Phosphodiesterase I0A Regulates Alcohol and Saccharin Self-Administration in Rats
}

\author{
Marian L Logrip*,', Leandro F Vendruscolo', Joel E Schlosburg', George F Koob' and Eric P Zorrilla*,' \\ 'Committee on the Neurobiology of Addictive Disorders, The Scripps Research Institute, La Jolla, CA, USA
}

A history of stress produces increases in rodent relapse-like alcohol self-administration behavior and regional brain gene expression of phosphodiesterase IOA (PDEIOA), a dual-specificity cyclic adenosine monophosphate/cyclic guanosine monophosphateinhibiting enzyme. Here, we tested the hypothesis that administration of TP-10, a specific PDEIOA inhibitor, would reduce alcohol self-administration in conditions predisposing to elevated self-administration. TP- 10 administration dose-dependently (0.562, $1.0 \mathrm{mg} / \mathrm{kg}$; subcutaneously) reduced relapse-like alcohol self-administration regardless of stress history enhancement of relapse-like behavior. TP-IO also reduced alcohol self-administration in genetically alcohol-preferring rats, as well as in alcohol-non-dependent and -dependent rats. Effective systemic TP-IO doses did not alter alcohol pharmacokinetics, significantly reduce motor activity or intrabout operant response speed, or promote a conditioned place aversion. TP- 10 also reduced saccharin self-administration, suggesting a general role for PDEIOA in the self-administration of reinforcing substances. PDEIOA inhibition in the dorsolateral striatum, but not the nucleus accumbens, reduced alcohol self-administration. Taken together, the results implicate dorsolateral striatum PDEIOA in facilitating alcohol intake and support further investigation of PDEIOA systems in the pathophysiology and potential treatment of substance use disorders.

Neuropsychopharmacology (2014) 39, I722-1731; doi:I0.1038/npp.2014.20; published online I9 February 2014

Keywords: alcohol use disorder; phosphodiesterase IOA enzyme; post-traumatic stress disorder; operant oral self-administration; reinforcement; dorsal striatum

\section{INTRODUCTION}

Alcohol use disorders, health problems with high recidivism, afflict $\sim 10 \%$ of the American population (Stinson et al, 2005). Relapse rates are particularly heightened in people with post-traumatic stress symptomatology (Driessen et al, 2008; McCarthy and Petrakis, 2010). Therefore, treatments effective in individuals with a history of traumatic stress are of great interest.

Phosphodiesterase 10A (PDE10A), a dual-specificity phosphodiesterase that inhibits cyclic adenosine monophosphate (cAMP) and cyclic guanosine monophosphate (cGMP) signaling (Fujishige et al, 1999; Loughney et al, 1999; Soderling et al, 1999), may mediate the relation between stress history and elevated relapse risk (Logrip and Zorrilla, 2012). PDE10A expression is enriched throughout the striatum, with lower expression in the cortex, hippocampus, and cerebellum (Seeger et al, 2003). Most studies into the biological role of PDE10A have used papaverine, an

*Correspondence: Dr ML Logrip or Dr EP Zorrilla, Committee on the Neurobiology of Addictive Disorders, The Scripps Research Institute, 10550 North Torrey Pines Road, SP30-2400, La Jolla, CA 92037, USA, Tel: + I 8587848026 (MLL) or + I 8587847416 (EPZ), Fax: + I 858784 7405, E-mail: mlogrip@scripps.edu or ezorrilla@ scripps.edu

Received 23 July 2013; revised 20 January 20।4; accepted 23 January 20I4; accepted article preview online 29 January 2014 inhibitor with only $\sim 9$-fold preference for PDE10A $v s$ PDE4D (Siuciak et al, 2006a), complicating the clarification of either enzyme's behavioral significance.

The recent development of highly selective PDE10A inhibitors, such as TP-10 (Schmidt et al, 2008), has enabled discrete manipulation of PDE10A function. Consistent with the striatal distribution and cAMP/cGMP-inhibiting action of PDE10A, systemic or local administration of TP-10, like papaverine, increased the striatal neuronal response to cortical stimulation (Threlfell et al, 2009). Both PDE10A inhibitors reduced conditioned avoidance of shock and dampened phencyclidine- or amphetamine-induced hyperlocomotion (Schmidt et al, 2008; Siuciak et al, 2006a). Furthermore, papaverine reduced anxiety-like behavior (Grauer et al, 2009), and TP-10 ameliorated amphetamineinduced deficits in auditory gating (Schmidt et al, 2008). Previously, this behavioral profile was suggested to indicate potential antipsychotic properties of PDE10A inhibitors (Miyamoto et al, 2005). However, the symptoms reduced by PDE10A inhibition also resemble several hallmarks of posttraumatic stress, including elevated anxiety-like behavior, impaired sensorimotor gating, heightened arousal, and hypervigilance (Bakshi et al, 2012; Stam, 2007; Stewart and White, 2008). Rats with a history of repeated footshock show increased Pde10a mRNA expression in the basolateral amygdala, correlated with alcohol preference during acquisition, and the prelimbic subdivision of the prefrontal 
cortex, correlated with 'relapse' alcohol self-administration (Logrip and Zorrilla, 2012). Here, we hypothesized that systemic treatment with the specific PDE10A inhibitor TP-10 would reduce alcohol self-administration, including: (1) in rats with elevated drinking subsequent to a history of stress, (2) in alcohol-preferring rats with high baseline anxiety-like behavior (Colombo et al, 1995) and (3) in alcohol-dependent rats allowed to self-administer during acute withdrawal, a period marked by anxiogenic-like behavior (Valdez et al, 2002). Because the striatum has a key role in instrumental conditioning (Belin et al, 2009) and displays the most prominent PDE10A expression (Seeger et al, 2003), we also hypothesized that a subdivision of the striatum might subserve PDE10A regulation of alcohol self-administration.

\section{MATERIALS AND METHODS}

\section{Subjects}

Adult male Wistar rats (Charles River Laboratories, Bar Harbor, ME; 175-250 g upon arrival) were individually housed for stress history studies $(n=28)$ or group-housed for alcohol pharmacokinetics $(n=10)$, brain site-specific PDE10A inhibition $(n=16)$, alcohol dependence $(n=19)$, reinforcer comparison $(n=24)$, and place conditioning $(n=16)$ studies. In addition, Sardinian alcohol-preferring sP rats of The Scripps Research Institute subline (Scr:sP; $n=7$ ) (Sabino et al, 2006) were bred in-house, grouphoused until the start of experiments, and then individually housed. Rats were housed in temperature- and humiditycontrolled rooms (reversed 12:12 h light:dark cycle), with chow (Harlan Teklad LM-485, Indianapolis, IN) and water available ad libitum. Procedures were approved by the Institutional Animal Care and Use Committee of The Scripps Research Institute and conformed to the National Institutes of Health Guide for the Care and Use of Animals.

\section{Materials}

TP-10 was generously provided by Pfizer (Groton, CT). Saccharin sodium salt, dimethyl sulfoxide (DMSO), and Cremophor EL were obtained from Sigma-Aldrich (St Louis, MO). (2-hydroxypropyl)- $\beta$-Cyclodextrin (HBC) was obtained from Sigma-Aldrich and Fischer Scientific (Pittsburgh, PA). Cannulas were purchased from Plastics One (Roanoke, VA).

\section{Operant Self-Administration Training}

Rats learned to self-administer alcohol as per a previously described protocol (Logrip and Zorrilla, 2012; Vendruscolo et al, 2012). Briefly, rats received two-bottle choice, limited access to alcohol (concentration matched to operant experiment, see below) and water in their home cages, and then acquired operant self-administration behavior during a single, 12 -h session in which responses at one lever delivered $0.1 \mathrm{ml}$ water (fixed-ratio 1 (FR1)), and responses at another lever had no scheduled consequences. Rats then commenced operant self-administration with $0.1 \mathrm{ml}$ reinforcers of $10 \%(\mathrm{v} / \mathrm{v})$ (stress history, site-specific infusion, reinforcer comparison; 1-h session vs inactive lever), $10 \%$ (w/v) (dependent/non-dependent; 30-min session $v s$ waterreinforced lever $\sim 6 \mathrm{~h}$ into withdrawal) or $20 \%(\mathrm{v} / \mathrm{v})$ (Scr:sP; 1-h session $v s$ water-reinforced lever) alcohol or $0.004 \%$ or $0.005 \%(\mathrm{w} / \mathrm{v})$ saccharin (stress history or reinforcer comparison, respectively; 1-h session $v s$ inactive lever). Operant sessions were reinforced on an FR1 schedule (each lever press elicited the reinforcer), or increased to FR3 (every third lever press elicited the reinforcer) after five FR1 sessions (stress history, brain site-specific infusion, reinforcer comparison). Sessions were run every 2-5 days. Stress history involved 3 days of footshock pre-exposure (60 $0.4-\mathrm{mA}$ shocks, 30 -s variable intertrial interval, coterminating with 5-s light cue) as described previously (Logrip and Zorrilla, 2012). Alcohol vapor dependence was performed as reported previously (Vendruscolo et al, 2012). Saccharin self-administration in stress history rats and progressive ratio (PR) responding in Scr:sP and dependent/nondependent rats were assessed after completing FR alcohol self-administration testing. PR session reinforcement escalatated as per the equation ( $4 \mathrm{e}^{\text {(reinforcers earned) } \times 0.75}-3.8$ ), after completing three lever presses to obtain the first reinforcer. PR sessions ended after the rat had not earned a reinforcer for $30 \mathrm{~min}$, up to $3 \mathrm{~h}$ (Scr:sP), or after a fixed 30-min duration (dependence). Behavioral conditioning details are provided in Supplementary Methods.

\section{TP-10 Treatment}

TP-10 (0, 0.1, 0.32, 0.562, and $1.0 \mathrm{mg} / \mathrm{kg}$ free base, dissolved in $33 \%(\mathrm{w} / \mathrm{v})$ HBC in saline) was injected subcutaneously $(1 \mathrm{ml} / \mathrm{kg})$ with a 30 -min pretreatment interval. For intracerebral infusion, TP-10 was dissolved in 5\% DMSO/5\% Cremophor $/ 90 \%$ saline and infused at doses of 0,1 and $3 \mathrm{nmol} / 0.5 \mu \mathrm{l}$ per side. Studies used within-subject, modified Latin square designs.

\section{Intracerebral Cannula Implantation and Site-Specific Infusion}

Under isoflurane anesthesia, rats were implanted with chronic bilateral 22-gauge guide cannulas slightly dorsal to the dorsolateral striatum (DLS: $\mathrm{AP}-0.2, \mathrm{ML} \pm 3.5, \mathrm{DV}$ $-3.8 \mathrm{~mm}$ relative to bregma) or the nucleus accumbens (NAc: AP +1.2, ML $\pm 1.0, \mathrm{DV}-5.5 \mathrm{~mm}$ ) (Paxinos and Watson, 1998). Rats were given 1 -week recovery before operant training. TP-10 infusions began once rats demonstrated stable baseline alcohol-reinforced responding ( $<20 \%$ variation/5 FR3 sessions). Twenty-eight-gauge infusers projecting $1.0 \mathrm{~mm}$ (DLS) or $1.5 \mathrm{~mm}$ (NAc) past the tip of the guide cannula were inserted, and rats were infused bilaterally at a rate of $0.25 \mu \mathrm{l} / \mathrm{min}$. Infusers remained in place for $2 \mathrm{~min}$ to allow diffusion. Operant sessions began 5 min later. Infusion sites were confirmed by histological analysis.

\section{Alcohol Pharmacokinetics}

Alcohol-naive rats were administered $1.0 \mathrm{mg} / \mathrm{kg} \mathrm{TP}-10$ or vehicle $30 \mathrm{~min}$ before intraperitoneal injection of $1 \mathrm{~g} / \mathrm{kg}$ alcohol (20\% (v/v) in saline). Tail blood was collected 10 , 60 , and $120 \mathrm{~min}$ after alcohol injection. Serum alcohol content was determined using the Analox AM1 Alcohol 
Analyzer (Analox Instruments USA, Lunenberg, MA). Subjects received both treatments 5 days apart in a counterbalanced manner.

\section{Locomotor Activity}

Locomotor activity was tested in photocell-equipped wire mesh cages (Valdez et al, 2003). Two days of environmental habituation ( $3 \mathrm{~h}$ per day) preceded the test day, on which rats received vehicle or $1.0 \mathrm{mg} / \mathrm{kg} \mathrm{TP}-10$ immediately before placement in the locomotor chambers. Locomotor activity was assessed 30-90 min after injection. Details are provided in Supplementary Methods.

\section{Place Conditioning}

To determine whether TP-10 produced aversive effects that might account for inhibition of operant responding, conditioned place aversion testing was conducted using a free choice, unbiased design in a three-chambered apparatus (Stinus et al, 2005). Pretest, conditioning, and test sessions were $20 \mathrm{~min}$ long, with saline and TP-10 (0 or $1 \mathrm{mg}$ / $\mathrm{kg}$ ) administered $30 \mathrm{~min}$ before confinement in the appropriate chamber. Details are provided in Supplementary Methods.

\section{Operant Microstructure Analysis}

To address the alternative explanation that TP-10 altered alcohol self-administration by nonspecifically impairing rats' ability to perform operant responses, the bout microstructure of active lever pressing by rats from the stress history study was analyzed. A bout was defined as a sequence of at least two reinforcers in which the maximum inter-response interval was $120 \mathrm{~s}$, a cutoff determined by frequency histogram analysis of $\log _{10}$-transformed durations of vehicle treatment day inter-response intervals $(n=8057)$ (Cottone et al, 2007; Tolkamp and Kyriazakis, 1999). A minority of inter-response interval durations were imputed by the general linear model for rats that did not produce alcohol self-administration bouts at the $1.0 \mathrm{mg} / \mathrm{kg}$ dose ( $n=3$ Control, $n=7$ Stress History-Normal Relapse, $n=1$ Stress History-High Relapse). Details of microstructure analyses are provided in Supplementary Methods.

\section{Data Analysis}

Stress History rats with 'relapse' self-administration $>95 \%$ of the Control distribution (mean +1.65 SDs) were classified as 'High Relapse' $(n=6)$; the remainder were categorized 'Normal Relapse' $(n=12)$. TP-10 treatment data were analyzed using one- or two-way analyses of variance (ANOVA) with repeated measures. Factors for systemic treatment included the repeated measures Dose and pretreatment Group, when applicable (Stress History, Dependence). Site-specific infusion analysis utilized ANOVA for between-subjects effects (Region, Treatment Order) and linear contrasts for the within-subjects comparisons. Alcohol pharmacokinetics data were analyzed using threeway repeated-measures ANOVA (within-subjects factors: Dose, Time; between-subjects factor: Day), as were place conditioning data (within-subjects factors: Day, Time; between-subjects factor: Dose). Post hoc comparisons were performed with Holm-Sidak tests. Statistical analyses were performed with Systat 12.0 and SigmaPlot 11.0 (Systat, Chicago, IL). Data are expressed as mean or least squares mean \pm SE. Details of statistical analyses are provided in Supplementary Methods.

\section{RESULTS}

\section{TP-10 Reduces Self-Administration in Rats with High Relapse-Like Alcohol Self-Administration}

To determine whether PDE10A has a functional role in relapse-like behaviors, rats without (Control) and with a history of stress (Stress History) were tested for the effects of PDE10A inhibition by TP-10 on relapse-like operant selfadministration. A subset of Stress History rats showed elevated 'relapse' alcohol self-administration levels (>95\% control distribution), despite comparable baseline selfadministration behavior (Supplementary Table S1), and were classified as High Relapse (alcohol-paired lever: $\mathrm{F}_{2,25}=4.05, p<0.05$; alcohol intake: $\mathrm{F}_{2,25}=3.68, p<0.05$, $v s$ Control). As shown in Figure 1, TP-10 dose-dependently reduced operant alcohol self-administration in all groups, including High Relapse rats. Main effects of Dose and trends toward Stress History effects were observed for alcoholreinforced lever presses (Dose: $F_{4,100}=19.32, p<0.001$; Stress History: $\mathrm{F}_{2,25}=3.05, p<0.07$; Figure 1a) and alcohol intake (Dose: $\mathrm{F}_{4,100}=18.70, p<0.001$; Stress History: $\mathrm{F}_{2,25}=2.73, \quad p<0.09$; Figure $\left.1 \mathrm{~b}\right)$, without Dose $\times$ Stress interaction. Post hoc analyses demonstrated that the 0.562 and $1.0 \mathrm{mg} / \mathrm{kg}$ TP-10 doses significantly reduced alcoholreinforced lever pressing and intake $v s$ vehicle conditions. TP-10 did not significantly alter non-reinforced lever pressing (Figure 1c; F's $<1.58$, $p$ 's $>0.18$ ) or alter alcohol pharmacokinetics, as the rate of serum alcohol clearance was unchanged by $1.0 \mathrm{mg} / \mathrm{kg}$ TP-10 (Figure 1d; main effect of Time: $\mathrm{F}_{2,16}=228.81, p<0.001$; no effect of Dose or interaction). Because doses lower than $0.562 \mathrm{mg} / \mathrm{kg}$ did not alter alcohol self-administration, subsequent studies focused on the effective 0.562 and $1.0 \mathrm{mg} / \mathrm{kg}$ TP-10 doses.

\section{TP-10 does not Significantly Change Motor Behavior at Effective Doses}

To determine how TP-10 altered alcohol self-administration and to address the alternative explanation that TP-10 might nonspecifically impair lever-pressing behavior, the effects of TP-10 on the microstructure of alcohol self-administration behavior and locomotor activity were analyzed. TP-10 could reduce alcohol self-administration without impairing response speed, because the interval between successive reinforced lever presses during self-administration bouts was not altered at the minimum effective dose $(0.562 \mathrm{mg} / \mathrm{kg}$; Figure 2a). A significant Dose effect $\left(\mathrm{F}_{3,64}=7.75, p<0.001\right)$ reflected slightly slower within-bout response rates in the $1.0 \mathrm{mg} / \mathrm{kg}$ TP-10 treatment group $v s$ all other groups; however, the $1.0 \mathrm{mg} / \mathrm{kg}$ dose group still could maintain rapid mean inter-response intervals of $\sim 3 \mathrm{~s}$ within bouts for Controls and Normal Relapse rats and of $\sim 1.5 \mathrm{~s}$ in High Relapse rats during the 1-h session. Lack of a global inhibition of motor activity by the $1.0 \mathrm{mg} / \mathrm{kg}$ dose also was 

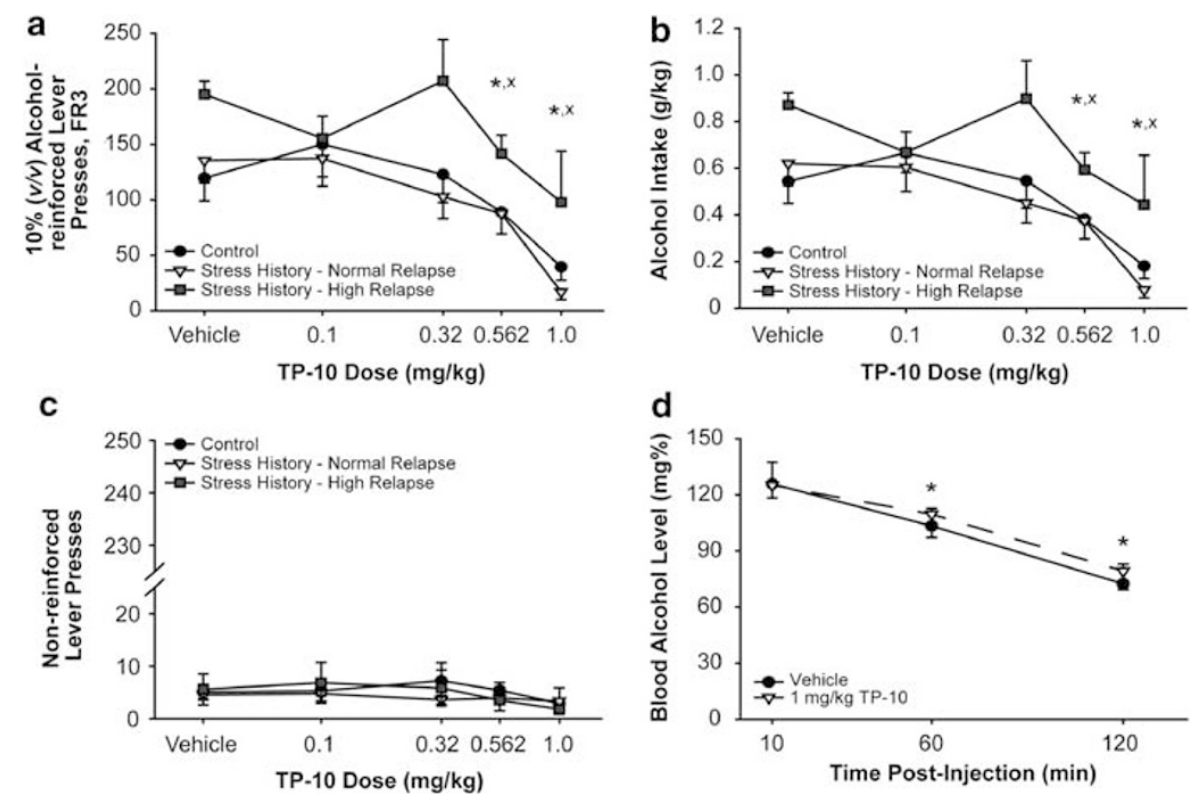

Figure I TP-I0 dose-dependently reduces operant alcohol self-administration without altering alcohol pharmacokinetics. (a-c) Rats self-administering $10 \%(\mathrm{~V} / \mathrm{v}$ ) alcohol on a fixed-ratio (FR) 3 schedule without (Control) or with past stress exposure (Stress History) were subcutaneously administered TP- I0 $(0.1,0.32,0.562$, or $1.0 \mathrm{mg} / \mathrm{kg}$ ) or its vehicle $30 \mathrm{~min}$ before the start of a I-h self-administration session. Responding on the alcohol-paired lever (a), weightnormalized alcohol intake (b), and responding on the non-reinforced lever (c) were measured. Data are expressed as mean \pm SE. * $p<0.05$ vs Vehicle, ${ }^{x} p<0.05$ vs all lower TP- 10 doses; $n=10$ Control, $n=12$ Stress History-Normal Relapse, $n=6$ Stress History-High Relapse. (d) Alcohol-naive rats were subcutaneously injected with $1.0 \mathrm{mg} / \mathrm{kg}$ TP- 10 or its vehicle $30 \mathrm{~min}$ before intraperitoneal administration of I g/kg of a $20 \%$ (v/v) alcohol solution. Tail blood was collected 10,60, and 120 min after alcohol injection and serum alcohol content was determined. $* p<0.05$ vs I0-min time point; $n=10$.

supported by lack of a comparably significant effect of TP-10 $(1.0 \mathrm{mg} / \mathrm{kg})$ on locomotor activity in familiar photocell cages (Table $1 ; F_{1,10}=3.43, p=0.09$ ).

\section{TP-10 Modifies the Microstructure of Operant Responding for Alcohol}

Rather than globally suppressing behavior, the microstructure analysis (Figure 2) showed that $1.0 \mathrm{mg} / \mathrm{kg}$, but not 0.32 or $0.562 \mathrm{mg} / \mathrm{kg}$, TP-10 increased the latency to obtain the first alcohol reinforcer (Figure 2b; Dose: $\mathrm{F}_{3,75}=11.97$, $p<0.001)$ and delayed the onset of lever pressing (Supplementary Figure S1A; Dose: $\mathrm{F}_{3,75}=3.18, p<0.05$ ). TP-10 decreased alcohol self-administration via dosedependent reductions in the number of bouts of alcohol self-administration (Figure $2 c^{c} ; F_{3,75}=16.17, p<0.001$ ), as well as the number of reinforcers earned in (Figure 2d; $\mathrm{F}_{3,75}=9.49, p<0.001$ ) and duration of (Supplementary Figure S1B; $\left.F_{3,75}=5.15, p<0.005\right)$ the load bout. Group effects indicated longer $\left(\mathrm{F}_{2,25}=4.31, p<0.05\right)$ and larger $\left(\mathrm{F}_{2,25}=6.45, p<0.01\right)$ load bouts in High Relapse $v s$ all other rats, without a Group $\times$ Dose interaction $(\mathrm{F}$ 's $<1.53$, $p$ 's $>0.18)$. TP-10 also reduced the size of later bouts of alcohol self-administration within the session (Supplementary Figure S1C; $F_{3,43}=4.70, p<0.01$ ).

\section{TP-10 Reduces Alcohol's Reinforcing Efficacy in Alcohol-Preferring and Alcohol-Dependent Rats}

The ability of TP-10 to reduce alcohol self-administration even in stress history rats with increased 'relapse' selfadministration suggested the hypothesis that PDE10A inhibition might similarly dampen elevated alcohol selfadministration in other rat models of heightened alcohol intake comorbid with anxiogenic-like behavior. Thus, we tested the effectiveness of TP-10 in alcohol-preferring Scr:sP rats (Sabino et al, 2006) and in acutely withdrawn alcoholdependent rats (Valdez et al, 2002; Zhao et al, 2007). TP-10 significantly reduced alcohol-reinforced lever pressing (Figures 3a and b) and alcohol intake (Figures 3c and d) in Scr:sP rats (Dose effects: $F_{2,12}=12.37, p<0.005$, Figure $3 \mathrm{a} ; \mathrm{F}_{2,12}=11.60, p<0.005$, Figure $3 \mathrm{c}$ ), as well as in alcohol-dependent and -non-dependent Wistar rats (Dose effects: $\mathrm{F}_{2,34}=4.61, p<0.05$, Figure $3 \mathrm{~b} ; \mathrm{F}_{2,34}=4.45$, $p<0.05$, Figure 3d). Lack of significant Dose $\times$ Group interactions indicated that TP-10 was similarly effective in reducing the heightened responding (Group, $\mathrm{F}_{1,17}=12.71$, $p<0.005$ ) and alcohol intake (Group, $\mathrm{F}_{1,17}=8.70, p<0.01$ ) of dependent $v s$ non-dependent rats. Although TP-10 decreased water-reinforced lever pressing in Scr:sP rats (Figure 3e; Dose: $\mathrm{F}_{2,12}=7.24, p<0.01$ ), it did not do so in either dependent or non-dependent Wistar rats (Figure 3f; Dose: $\mathrm{F}_{2,34}=0.89, p=0.42$ ).

A PR schedule of reinforcement was used to test the hypothesis that PDE10A inhibition reduced the reinforcing efficacy of alcohol. TP-10 significantly decreased PR responding for alcohol in Scr:sP (Figure 3g; Dose: $F_{2,12}=5.26$, $p<0.05$ ) and dependent/non-dependent rats (Figure $3 \mathrm{~h}$; main effects of Group: $\mathrm{F}_{1,17}=4.51, p<0.05$; and Dose: $\left.\mathrm{F}_{1,17}=18.57, \quad p<0.001\right)$. Time-course analysis revealed dose-dependent reductions in alcohol-reinforced lever presses within the first 5 min of self-administration in both Scr:sP (Supplementary Figure S2A; Dose $\times$ Time interaction: $F_{10,60}=2.90, p<0.01$ ) and dependent/non-dependent 

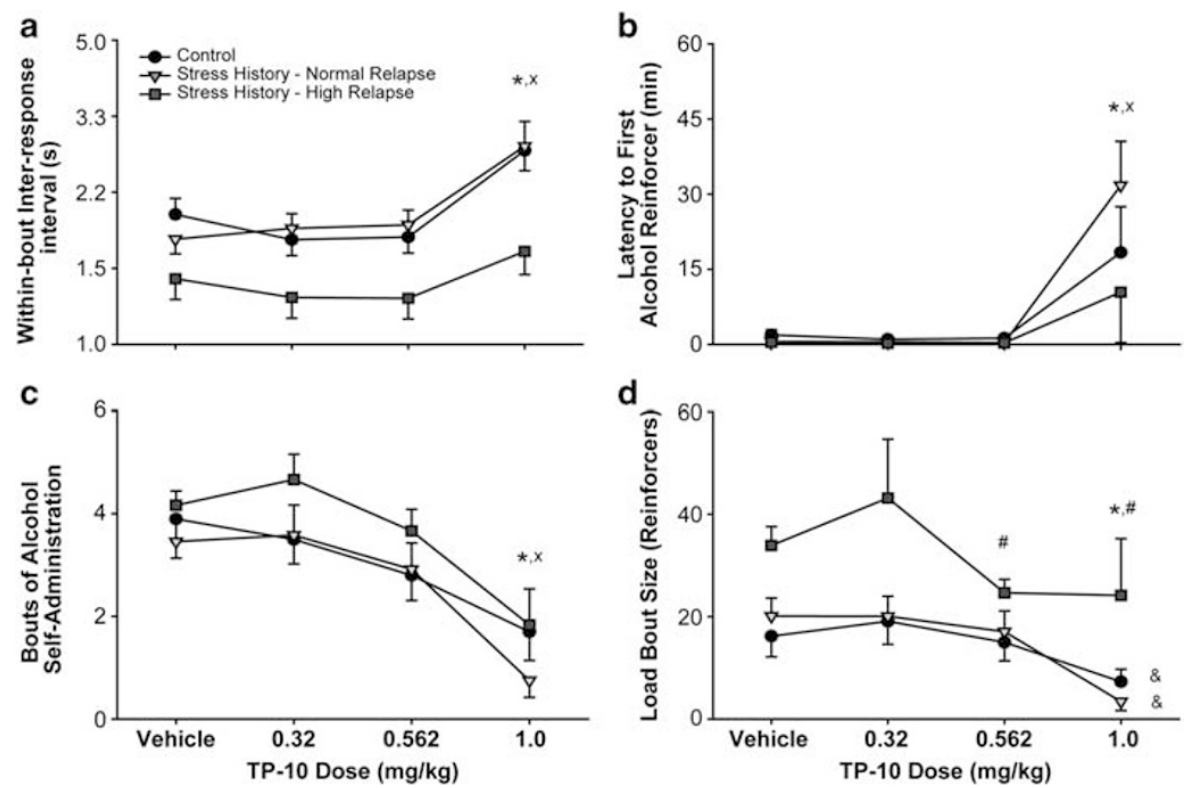

Figure 2 TP-I0 modulates the microstructure of alcohol self-administration behavior. The pattern of responses within the I-h alcohol self-administration session was assessed in rats pretreated with the two effective doses, as well as one subthreshold dose, of TP- 10 ( $0.32,0.562$, or $1.0 \mathrm{mg} / \mathrm{kg})$ or its vehicle. Bouts of self-administration within the I-h session were defined as sequences of responding in which at least two reinforcers were obtained and successive alcohol-paired lever presses were separated by no more than $2 \mathrm{~min}$. Panels depict (a) average duration of intervals between successive depressions of the alcohol-paired lever within bouts of alcohol self-administration; (b) latency from the start of the session until attainment of the first alcohol reinforcer; (c) number of bouts within the session; and (d) number of reinforcers earned during the load, or first, bout. Note the logarithmic 10 scale of inter-response interval durations, reflecting the approximately log normal distribution. Data are expressed as least squares mean (LSM) \pm SE (a, imputing values as needed for the $1.0 \mathrm{mg} / \mathrm{kg}$ dose) or mean \pm SE (b-d). ${ }^{*} p<0.05$ vs Vehicle, ${ }^{\#} p<0.05$ vs $0.32 \mathrm{mg} / \mathrm{kg}$ TP- $10,{ }^{\times} p<0.05$ vs all lower TP- 10 doses; ${ }^{*} p<0.05$ vs Stress History-High (Group Effect); $n=10$ Control, $n=12$ Stress History-Normal Relapse, $n=6$ Stress History-High Relapse.

Table I TP-IO does not Produce a Conditioned Place Aversion or Significantly Alter Locomotor Activity

\begin{tabular}{|c|c|c|c|}
\hline & Pretest & Test & Time difference \\
\hline \multicolumn{4}{|c|}{ Place conditioning ${ }^{\mathrm{a}}$} \\
\hline \multicolumn{4}{|c|}{ Chamber time (s) } \\
\hline Vehicle & $343 \pm 23$ & $288 \pm 26$ & $-55 \pm 25$ \\
\hline TP- 10 & $345 \pm 7$ & $291 \pm 23$ & $-54 \pm 22$ \\
\hline \multicolumn{4}{|c|}{ Percent total chamber time } \\
\hline Vehicle & $34.3 \pm 1.9$ & $31.1 \pm 2.3$ & \\
\hline TP- 10 & $34.4 \pm 1.0$ & $31.7 \pm 2.2$ & \\
\hline \multicolumn{4}{|c|}{ Locomotor activity (beam breaks) } \\
\hline Vehicle & & $339 \pm 71$ & \\
\hline TP- 10 & & $188 \pm 40$ & \\
\hline
\end{tabular}

Data are presented as mean \pm SE. Vehicle: $33 \% \mathrm{HBC}$; TP-10: $1.0 \mathrm{mg} / \mathrm{kg}$.

${ }^{\mathrm{a}} \mathrm{N}=8$ per group.

${ }^{\mathrm{b}} \mathrm{N}=6$ per group.

rats (Supplementary Figure S2B; Dose $\times$ Time interaction: $\left.\mathrm{F}_{5,85}=3.84, p<0.005\right)$.

\section{TP-10 Reduces Saccharin and Alcohol Self-Administration Equivalently}

To determine whether TP-10 generally reduced seeking of appetitive substances or specifically inhibited alcohol self-administration, rats were tested in parallel for TP-10 effects on operant responding for $0.005 \%(\mathrm{w} / \mathrm{v})$ saccharin or $10 \%(\mathrm{v} / \mathrm{v})$ alcohol. As shown in Figure 4a, TP-10 dosedependently reduced alcohol and saccharin self-administration similarly (Dose: $\mathrm{F}_{2,32}=10.41, p<0.001$ ). Post hoc analyses showed significant reduction in self-administration at both 0.562 and $1.0 \mathrm{mg} / \mathrm{kg}$ doses, whereas inactive lever presses were not significantly altered (Figure 4b; Dose: $\left.\mathrm{F}_{2,32}=2.87, p>0.07\right)$. TP-10 also dose-dependently reduced $0.004 \%(\mathrm{w} / \mathrm{v})$ saccharin reinforced-lever presses in Control and Stress History rats (Supplementary Figure S3; $\left.\mathrm{F}_{2,50}=10.75, p<0.001\right)$, an effect restricted to the higher $1.0 \mathrm{mg} / \mathrm{kg}$ dose $(p<0.001$ vs Vehicle). No effects of Stress History or interactions with Dose were observed.

\section{TP-10 does not Produce a Conditioned Place Aversion}

Because TP-10 reduced both alcohol and saccharin selfadministration, potential aversive effects of TP-10 were assessed using place conditioning. TP-10 did not generate significant place aversion or preference $v s$ vehicle (Table 1). Vehicle- and TP-10-treated rats spent equivalent percent time in the conditioned chamber during both pretest and test sessions (Dose: $F_{1,14}=0.03, p=0.86$, Dose $\times$ Test Session: $\left.\mathrm{F}_{1,14}=0.03, p=0.87\right)$.

\section{PDE10A in the Dorsolateral Striatum Modulates Alcohol Self-Administration}

Because TP-10 reduced alcohol self-administration across all groups, investigation of site-specific efficacy focused on regions of the striatum, where expression of PDE10A is 

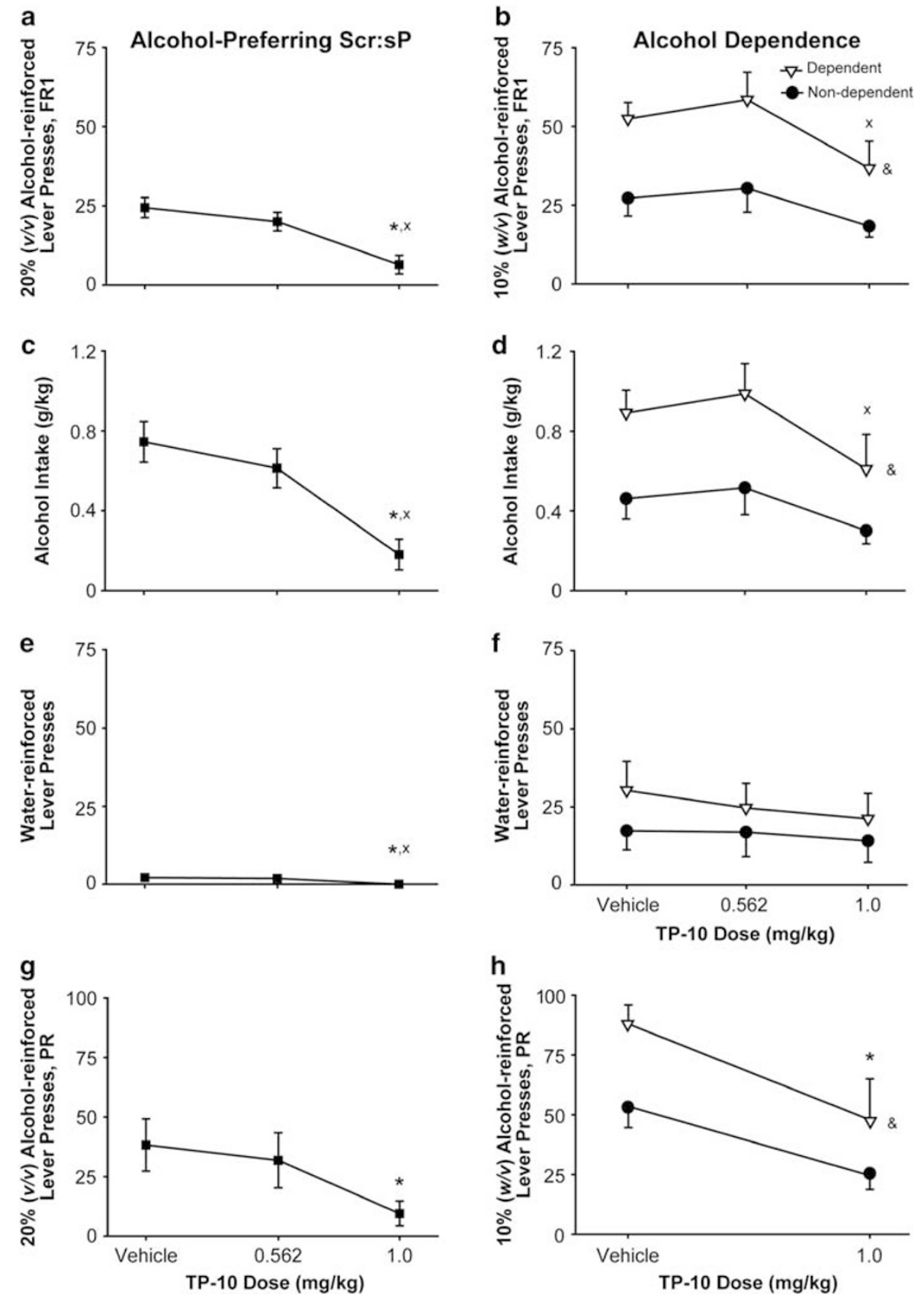

Figure 3 TP- 10 reduces alcohol self-administration and alcohol-seeking behavior in alcohol-preferring and -dependent rats. Sardinian alcohol-preferring rats of The Scripps Research Institute subline (Scr:sP) self-administering 20\% (v/v) alcohol vs water (a, c, and e) and alcohol-dependent and -non-dependent Wistar rats (Alcohol Dependence) self-administering $10 \%(\mathrm{w} / \mathrm{v})$ alcohol vs water (b, $d$, and $f$ ) on fixed-ratio (FR) I schedules were subcutaneously administered TP-10 (0.562 or $1.0 \mathrm{mg} / \mathrm{kg})$ or its vehicle $30 \mathrm{~min}$ before the start of a I-h (a, c, and e) or 30-min (b, d, and f) self-administration session. Responding on the alcohol-paired lever ( $a$ and b), weight-normalized intake ( $c$ and $d$ ) and water-reinforced lever presses (e and f) were measured. ( $g$ and $h$ ) Rats self-administering alcohol under progressive ratio (PR) reinforcement by 20\% (v/v) alcohol (Scr:sP, g) or I0\% (w/v) alcohol (Alcohol Dependence, h) were treated with TP-I0 (0.562 (Scr:sP only) or $1.0 \mathrm{mg} / \mathrm{kg}$ ) or its vehicle $30 \mathrm{~min}$ before the start of the operant session. Data are expressed as mean \pm SE. ${ }^{*} p<0.05$ vs Vehicle, ${ }^{\times} p<0.05$ vs $0.562 \mathrm{mg} / \mathrm{kg}$ TP- $10 ;{ }^{\circledR} p<0.05$ vs Non-dependent; $n=7$ Scr:sP, $n=10$ Dependent, $n=9$ Non-dependent.

highest (Seeger et al, 2003) and which has been implicated in alcohol self-administration (Nestby et al, 1999). We assessed involvement of PDE10A in the NAc, a region key to dopaminergic modulation of goal-directed behavior (Carelli, 2002), and the DLS, where acute manipulations have reduced alcohol self-administration in a motorindependent manner (Jeanblanc et al, 2009). Analysis of self-administration following TP-10 infusion into the DLS (Figure 5a) and NAc (Figure 5b) revealed that $3 \mathrm{nmol} \mathrm{TP}-10$ infusion into the DLS, but not NAc (Figure $5 \mathrm{c}$; time course Supplementary Figure S4), significantly reduced alcoholreinforced lever presses (Dose: DLS, $\mathrm{F}_{1,5}=6.84, p<0.05$; NAc, $F_{1,5}=0.33, p=0.59$ ). On the other hand, perhaps owing to high variability among the data, inadequate power, 

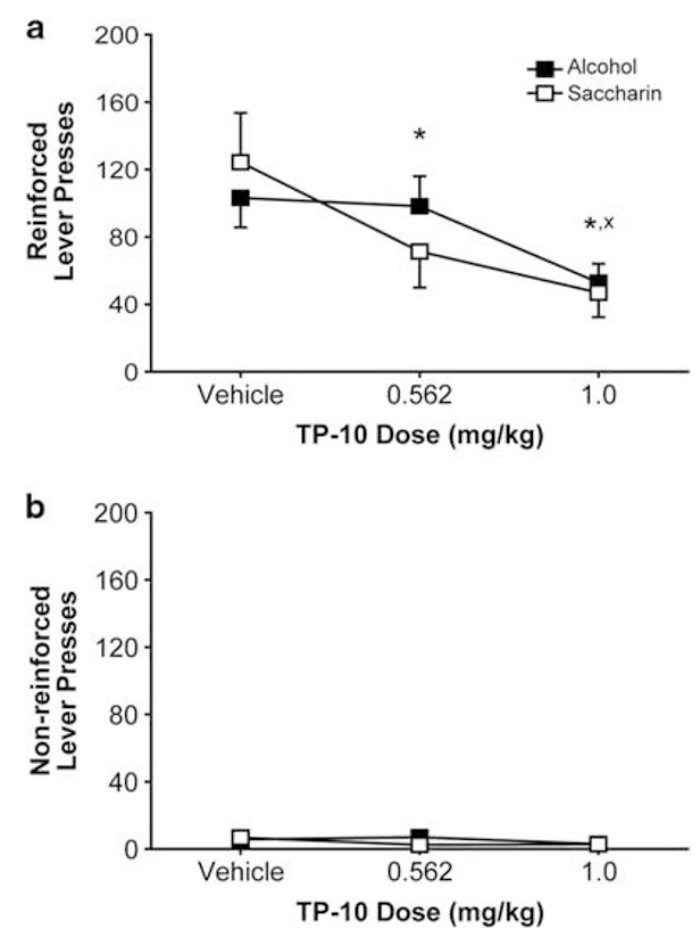

Figure 4 Saccharin and alcohol self-administration are comparably reduced by TP-10. Rats self-administering 10\% (v/v) alcohol or $0.005 \%$ $(\mathrm{w} / \mathrm{v})$ saccharin on a fixed-ratio 3 schedule were pretreated subcutaneously with TP-I0 $(0.562$ or $1.0 \mathrm{mg} / \mathrm{kg})$ or its vehicle $30 \mathrm{~min}$ before the start of a I-h self-administration session. Presses on the reinforced (a) and non-reinforced (b) levers are depicted. Data are expressed as mean \pm SE. ${ }^{*} p<0.05$ vs Vehicle, ${ }^{x} p<0.05$ vs $0.562 \mathrm{mg} / \mathrm{kg}$ TP- $10 ; n=9$ per group.

or lack of efficacy of the lower dose in either brain region, no significant Dose $\times$ Region effect was observed if DLS and NAc were analyzed within the same model (Dose $\times$ Region: $\mathrm{F}_{2,20}=0.14, p=0.87$ ). Thus, we cannot rule out the null hypothesis that TP-10 exerts similar effects in the DLS and NAc. No significant reduction in non-reinforced lever presses was observed (Figure 5d, Dose: DLS, $F_{1,5}=5.80$, $\left.p>0.06 ; \mathrm{NAc}, \mathrm{F}_{1,5}=2.27, p>0.19\right)$.

\section{DISCUSSION}

The current studies demonstrate a role for the cAMP/ cGMP-hydrolyzing enzyme PDE10A in maintaining alcohol self-administration, possibly via activity in the DLS. Inhibition of PDE10A activity by systemic administration of TP-10 dose-dependently reduced alcohol self-administration (Supplementary Figure S5). TP-10 was effective in rats with high levels of relapse-like self-administration subsequent to a history of stress, as well as in alcoholpreferring and alcohol-dependent rats. Decreased alcohol intake did not result from altered alcohol pharmacokinetics, aversive effects, or global motor inhibition. Specifically, the highest dose of TP-10 tested $(1.0 \mathrm{mg} / \mathrm{kg})$ did not alter serum ethanol clearance, produce a conditioned place aversion, or reduce locomotor activity. Furthermore, the minimum effective dose $(0.562 \mathrm{mg} / \mathrm{kg})$ did not slow operant response speed within bouts of alcohol self-administration or reduce concurrent rates of non-reinforced or water-reinforced lever pressing. Rather, the efficacy of TP-10 to decrease PR alcohol self-administration, which is less prone to ratesensitive confounds, suggests that TP-10 decreased alcohol self-administration by reducing alcohol's reinforcing efficacy. Accordingly, in FR self-administration, TP-10 most potently $(0.562 \mathrm{mg} / \mathrm{kg})$ reduced alcohol intake by promoting earlier cessation of operant self-administration behavior, decreasing the number of reinforcers earned in later bouts in the session. At the higher dose $(1.0 \mathrm{mg} / \mathrm{kg}), \mathrm{TP}-10$ also increased the latency to initiate alcohol self-administration and reduced the number of alcohol self-administration bouts, the load bout size and the within-bout rate of alcohol-directed responding. Because TP-10 reduced saccharin and alcohol self-administration with similar potency, the results suggest a broad role for PDE10A in regulating the motivation to self-administer appetitive substances.

\section{PDE10A Activity Supports Motivated Responding for Reinforcers}

Previously we reported a direct relationship between Pde10a mRNA expression and alcohol self-administration, particularly in rats with a stress history (Logrip and Zorrilla, 2012). Here, we show that systemic treatment with TP-10 dosedependently reduced alcohol self-administration in rats with stress history, alcohol dependence, or genetic predisposition to high levels of alcohol intake. Interestingly, the cAMP-selective PDE4 inhibitor rolipram also reduced home cage alcohol intake in mice and rats ( $\mathrm{Hu}$ et al, 2011; Wen et al, 2012) and operant alcohol self-administration in rats (Wen et al, 2012), without effect on sucrose consumption (Hu et al, 2011; Wen et al, 2012). Although some effects of PDE10A and PDE4 inhibition are similar, PDE10A inhibition displays more general efficacy to decrease operant selfadministration of both natural and drug reinforcers, suggesting a possible divergence in mechanism between the two phosphodiesterases, perhaps via different regional expression (Perez-Torres et al, 2000; Seeger et al, 2003), subcellular distribution (Nishi et al, 2008), or effects on striatal signaling pathways (Nishi et al, 2008). Consistent with the present results, inhibition of PDE10A by genetic deletion or chronic antagonist treatment reduced intake of highly palatable high-fat diets in mice, without altering standard chow intake (Nawrocki et al, 2013), supporting PDE10A regulation of motivation for highly reinforcing substances. Conversely, inhibition of PDE4 did not reduce high-fat diet intake (Park et al, 2012), indicating differential roles for PDE10A vs PDE4 in regulating motivated behaviors. Nonetheless, understanding the comparability of these two PDE inhibitor families remains incomplete, because effects of PDE4 inhibitors on alcohol self-administration under higher work requirements (eg, FR3, PR) or in models of excessive alcohol drinking have not been reported.

Most studies addressing the behavioral impact of PDE10A inhibition or genetic deletion have focused on antipsychotic (Grauer et al, 2009; Schmidt et al, 2008; Siuciak et al, 2006a, b; Smith et al, 2012; Weber et al, 2009) or memoryenhancing (Grauer et al, 2009; Liddie et al, 2012; Piccart et al, 2011; Rodefer et al, 2012; Smith et al, 2012) effects. However, tests with putative predictive validity for antipsychotic pharmacological potential also involve reward- 

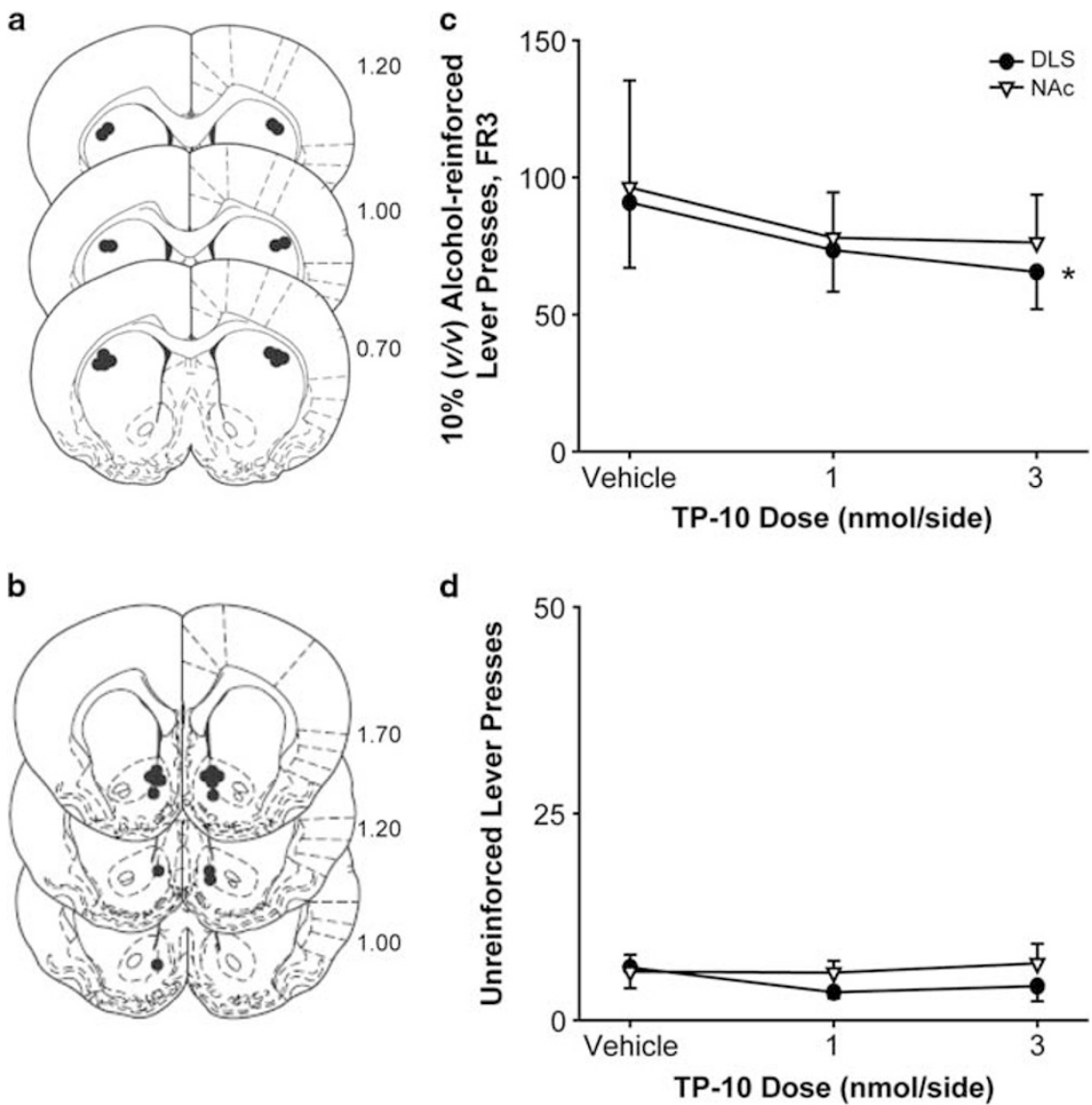

Figure 5 TP-IO infusion into the dorsolateral striatum, but not into the nucleus accumbens, significantly reduces alcohol self-administration. Rats selfadministering I0\% (v/v) alcohol on a fixed-ratio 3 schedule were bilaterally infused with TP- 10 (I or $3 \mathrm{nmol}$ per side) or its vehicle into the dorsolateral striatum (DLS) or nucleus accumbens (NAc) 5 min before the start of a I-h self-administration session. (a) and (b) depict infusion locations for DLS (a) and NAc (b), adapted with permission from Paxinos and Watson (1998). Responding on the alcohol-reinforced lever (c) and on the non-reinforced lever (d) was measured. Data are expressed as mean \pm SE. $* p<0.05$ vs vehicle infusion, main effect of Dose, $n=8$ DLS, $n=8$ NAc.

related behavior, such as locomotor activation upon acute administration of a drug of abuse. Pharmacological inhibition or genetic deletion of PDE10A blunts the ability of amphetamine (Schmidt et al, 2008; Siuciak et al, 2006a, b; Sotty et al, 2009) and the NMDA antagonists phencyclidine (Schmidt et al, 2008; Siuciak et al, 2006a) and MK-801 (Smith et al, 2012) to elicit locomotor activity in rodents. Taken together with the present results, these findings support a role for PDE10A in reinforcement or reward processes, but this function may be more complex than direct inhibition of reward, because TP-10 did not produce a conditioned place aversion (or preference). Furthermore, the PDE10A-preferring inhibitor papaverine did not alter extinction of cocaine conditioned place preference (Liddie et al, 2012), as might be expected if PDE10A served as a general regulator of reward system function. Still, papaverine modestly increased intracranial self-stimulation current thresholds in rats (Mumford and Holtzman, 1990), suggesting that PDE10A may modulate the reinforcing effects of other appetitive stimuli. This hypothesis is consistent with the prominent expression of PDE10A in the striatum (Seeger et al, 2003) and the ability of intra-DLS TP-10 to reduce alcohol self-administration. The mechanisms and behavioral constructs that contribute to the potent effects of PDE10A inhibition on alcohol and saccharin self-administration remain to be determined.

\section{Dorsolateral Striatum PDE10A and Modulation of Operant Self-Administration}

The present results implicate DLS PDE10A in supporting operant responding for alcohol (and perhaps also saccharin) reinforcers. At the molecular level, PDE10A may modulate striatal activity via inhibition of cAMP- and cGMP-dependent signaling pathways. Both cAMP and cGMP regulate striatal neuronal activity, as both participate in the generation of long-term depression (LTD) (Calabresi et al, 1999, 2000). Broad-spectrum inhibition of cGMPdependent phosphodiesterases increased resting membrane potential and spontaneous spike frequency in the central dorsal striatum in vivo (West and Grace, 2004). In a DLS slice preparation, greatly elevated intracellular cAMP levels switched the response to high-frequency stimulation from LTD to potentiation (Kheirbek et al, 2009). TP-10 similarly increased cortically evoked neuronal activation in the central dorsal striatum, particularly in striatopallidal (dopamine D2 receptor-expressing) neurons (Threlfell et al, 2009). Furthermore, systemic TP-10 administration significantly increased dopamine turnover in the DLS and NAc, with greater potency in the DLS (Schmidt et al, 2008). Application of either TP-10 or papaverine produced molecular and electrophysiological response profiles similar to the application of D2 receptor antagonists (Nishi et al, 
2008; Threlfell et al, 2009), likely via a postsynaptic mechanism of action (Nishi et al, 2008). Papaverine modulation of cAMP signaling suggests a more prominent, although non-exclusive, role for PDE10A in D2-expressing medium spiny neurons (Nishi et al, 2008); whether such a pattern exists for cGMP is as yet unknown. Interestingly, phosphorylation of extracellular signal-regulated kinase (Siuciak et al, 2006a), which is a downstream consequence of PDE10A inhibition, is required for intra-DLS infusion of brain-derived neurotrophic factor to decrease alcohol self-administration (Jeanblanc et al, 2013). Investigating this and other downstream signaling partners in the DLS that may mediate PDE10A reduction of alcohol and saccharin self-administration presents an interesting line of future study. Because poor solubility limited the doses of TP-10 that could be administered and because we did not observe a significant Dose $\times$ Region interaction on TP-10 effects between the DLS and NAc, we cannot exclude a role also for NAc PDE10A in modulating reinforcement processes. Nonetheless, the present results raise the hypothesis that DLS PDE10A may participate in the generation or maintenance of compulsive alcoholseeking.

\section{CONCLUSION}

We report that a selective PDE10A inhibitor potently reduced alcohol and saccharin self-administration, even in previously stressed rats with high 'relapse' alcohol selfadministration, as well as in alcohol-dependent and genetically alcohol-preferring rat models of excessive drinking. This action may result, at least in part, from modulation of PDE10A activity in the DLS. In combination with our earlier work (Logrip and Zorrilla, 2012), the data implicate PDE10A inhibitors for further study in rewardrelated disorders, given their general ability to reduce alcohol and saccharin self-administration.

\section{FUNDING AND DISCLOSURE}

Unrelated to the current manuscript, GFK receives compensation for consulting for Addex Pharmaceuticals, Arkeo Pharmaceuticals, Embera NeuroTherapeutics, and Psychogenics. EPZ holds unrelated patents on anti-ghrelin immunotherapy, for which he receives royalties. MLL has previously been compensated for scientific editing unrelated to the current manuscript. The authors declare no conflict of interest.

\section{ACKNOWLEDGEMENTS}

We thank Christopher Schmidt and Pfizer for the generous provision of TP-10. We also thank Tiffany Andres, Michelle Hong, Sameeha Khalid, Ryan Muir, Rheall Roquet, and Nathaniel Tran for technical assistance and Jennifer Frihauf and Sarah Parylak for helpful discussions. Research funding was provided by the Pearson Center for Alcoholism Research, as well as the National Institutes of Health Grants DK026741 from the National Institute of Diabetes and Digestive and Kidney Diseases, and AA006420, AA008459, and AA018914 from the National Institute on Alcohol Abuse and Alcoholism. The content is solely the responsibility of the authors and does not necessarily represent the official views of the National Institutes of Health, the National Institute of Alcohol Abuse and Alcoholism, or the National Institute of Neurological Disorders and Stroke. This is research publication number 25012 from The Scripps Research Institute.

\section{REFERENCES}

Bakshi VP, Alsene KM, Roseboom PH, Connors EE (2012). Enduring sensorimotor gating abnormalities following predator exposure or corticotropin-releasing factor in rats: a model for PTSD-like information-processing deficits? Neuropharmacology 62: 737-748.

Belin D, Jonkman S, Dickinson A, Robbins TW, Everitt BJ (2009). Parallel and interactive learning processes within the basal ganglia: relevance for the understanding of addiction. Behav Brain Res 199: 89-102.

Calabresi P, Gubellini P, Centonze D, Picconi B, Bernardi G, Chergui $\mathrm{K}$ et al (2000). Dopamine and cAMP-regulated phosphoprotein $32 \mathrm{kDa}$ controls both striatal long-term depression and long-term potentiation, opposing forms of synaptic plasticity. J Neurosci 20: 8443-8451.

Calabresi P, Gubellini P, Centonze D, Sancesario G, Morello M, Giorgi M et al (1999). A critical role of the nitric oxide/cGMP pathway in corticostriatal long-term depression. J Neurosci 19: 2489-2499.

Carelli RM (2002). The nucleus accumbens and reward: neurophysiological investigations in behaving animals. Behav Cogn Neurosci Rev 1: 281-296.

Colombo G, Agabio R, Lobina C, Reali R, Zocchi A, Fadda F et al (1995). Sardinian alcohol-preferring rats: a genetic animal model of anxiety. Physiol Behav 57: 1181-1185.

Cottone P, Sabino V, Nagy TR, Coscina DV, Zorrilla EP (2007). Feeding microstructure in diet-induced obesity susceptible versus resistant rats: central effects of urocortin 2. J Physiol 583(Part 2): 487-504.

Driessen M, Schulte S, Luedecke C, Schaefer I, Sutmann F, Ohlmeier M et al (2008). Trauma and PTSD in patients with alcohol, drug, or dual dependence: a multi-center study. Alcohol Clin Exp Res 32: 481-488.

Fujishige K, Kotera J, Michibata H, Yuasa K, Takebayashi S, Okumura K et al (1999). Cloning and characterization of a novel human phosphodiesterase that hydrolyzes both cAMP and cGMP (PDE10A). J Biol Chem 274: 18438-18445.

Grauer SM, Pulito VL, Navarra RL, Kelly MP, Kelley C, Graf R et al (2009). Phosphodiesterase 10A inhibitor activity in preclinical models of the positive, cognitive, and negative symptoms of schizophrenia. J Pharmacol Exp Ther 331: 574-590.

$\mathrm{Hu}$ W, Lu T, Chen A, Huang Y, Hansen R, Chandler LJ et al (2011). Inhibition of phosphodiesterase-4 decreases ethanol intake in mice. Psychopharmacology (Berl) 218: 331-339.

Jeanblanc J, He DY, Carnicella S, Kharazia V, Janak PH, Ron D (2009). Endogenous BDNF in the dorsolateral striatum gates alcohol drinking. J Neurosci 29: 13494-13502.

Jeanblanc J, Logrip ML, Janak PH, Ron D (2013). BDNF-mediated regulation of ethanol consumption requires the activation of the MAP kinase pathway and protein synthesis. Eur J Neurosci 37: 607-612.

Kheirbek MA, Britt JP, Beeler JA, Ishikawa Y, McGehee DS, Zhuang X (2009). Adenylyl cyclase type 5 contributes to corticostriatal plasticity and striatum-dependent learning. J Neurosci 29: 12115-12124.

Liddie S, Anderson K, Paz A, Itzhak Y (2012). The effect of phosphodiesterase inhibitors on extinction of cocaine-induced 
conditioned place preference in mice. J Psychopharmacol 26: 1375-1382.

Logrip ML, Zorrilla EP (2012). Stress history increases alcohol intake in relapse: relation to phosphodiesterase 10A. Addict Biol 17: 920-933.

Loughney K, Snyder PB, Uher L, Rosman GJ, Ferguson K, Florio VA (1999). Isolation and characterization of PDE10A, a novel human 3', 5'-cyclic nucleotide phosphodiesterase. Gene 234: 109-117.

McCarthy E, Petrakis I (2010). Epidemiology and management of alcohol dependence in individuals with post-traumatic stress disorder. CNS Drugs 24: 997-1007.

Miyamoto S, Duncan GE, Marx CE, Lieberman JA (2005). Treatments for schizophrenia: a critical review of pharmacology and mechanisms of action of antipsychotic drugs. Mol Psychiatry 10: 79-104.

Mumford GK, Holtzman SG (1990). Methylxanthines elevate reinforcement threshold for electrical brain stimulation: role of adenosine receptors and phosphodiesterase inhibition. Brain Res 528: 32-38.

Nawrocki AR, Rodriguez CG, Toolan DM, Price O, Henry M, Forrest $G$ et al (2013). Genetic deletion and pharmacological inhibition of PDE10A protects mice from diet-induced obesity and insulin resistance. Diabetes 63: 300-311.

Nestby P, Vanderschuren LJ, De Vries TJ, Mulder AH, Wardeh G, Hogenboom F et al (1999). Unrestricted free-choice ethanol selfadministration in rats causes long-term neuroadaptations in the nucleus accumbens and caudate putamen. Psychopharmacology (Berl) 141: 307-314.

Nishi A, Kuroiwa M, Miller DB, O'Callaghan JP, Bateup HS, Shuto $\mathrm{T}$ et al (2008). Distinct roles of PDE4 and PDE10A in the regulation of cAMP/PKA signaling in the striatum. J Neurosci 28 : 10460-10471.

Park SJ, Ahmad F, Philp A, Baar K, Williams T, Luo H et al (2012). Resveratrol ameliorates aging-related metabolic phenotypes by inhibiting cAMP phosphodiesterases. Cell 148: 421-433.

Paxinos G, Watson C (1998). The Rat Brain in Stereotaxic Coordinates. 4th edn Academic Press: New York, NY.

Perez-Torres S, Miro X, Palacios JM, Cortes R, Puigdomenech P, Mengod G (2000). Phosphodiesterase type 4 isozymes expression in human brain examined by in situ hybridization histochemistry and $\left[{ }^{3} \mathrm{H}\right]$ rolipram binding autoradiography. Comparison with monkey and rat brain. J Chem Neuroanat 20: 349-374.

Piccart E, Gantois I, Laeremans A, de Hoogt R, Meert T, Vanhoof G et al (2011). Impaired appetitively as well as aversively motivated behaviors and learning in PDE10A-deficient mice suggest a role for striatal signaling in evaluative salience attribution. Neurobiol Learn Mem 95: 260-269.

Rodefer JS, Saland SK, Eckrich SJ (2012). Selective phosphodiesterase inhibitors improve performance on the ED/ID cognitive task in rats. Neuropharmacology 62: 1182-1190.

Sabino V, Cottone P, Koob GF, Steardo L, Lee MJ, Rice KC et al (2006). Dissociation between opioid and CRF1 antagonist sensitive drinking in Sardinian alcohol-preferring rats. Psychopharmacology (Berl) 189: 175-186.

Schmidt CJ, Chapin DS, Cianfrogna J, Corman ML, Hajos M, Harms JF et al (2008). Preclinical characterization of selective phosphodiesterase 10A inhibitors: a new therapeutic approach to the treatment of schizophrenia. J Pharmacol Exp Ther 325: 681-690.

Seeger TF, Bartlett B, Coskran TM, Culp JS, James LC, Krull DL et al (2003). Immunohistochemical localization of PDE10A in the rat brain. Brain Res 985: 113-126.

Siuciak JA, Chapin DS, Harms JF, Lebel LA, McCarthy SA, Chambers L et al (2006a). Inhibition of the striatum-enriched phosphodiesterase PDE10A: a novel approach to the treatment of psychosis. Neuropharmacology 51: 386-396.

Siuciak JA, McCarthy SA, Chapin DS, Fujiwara RA, James LC, Williams RD et al (2006b). Genetic deletion of the striatumenriched phosphodiesterase PDE10A: evidence for altered striatal function. Neuropharmacology 51: 374-385.

Smith SM, Uslaner JM, Cox CD, Huszar SL, Cannon CE, Vardigan JD et al (2012). The novel phosphodiesterase 10A inhibitor THPP-1 has antipsychotic-like effects in rat and improves cognition in rat and rhesus monkey. Neuropharmacology 64: 215-223.

Soderling SH, Bayuga SJ, Beavo JA (1999). Isolation and characterization of a dual-substrate phosphodiesterase gene family: PDE10A. Proc Natl Acad Sci USA 96: 7071-7076.

Sotty F, Montezinho LP, Steiniger-Brach B, Nielsen J (2009). Phosphodiesterase $10 \mathrm{~A}$ inhibition modulates the sensitivity of the mesolimbic dopaminergic system to D-amphetamine: involvement of the D1-regulated feedback control of midbrain dopamine neurons. J Neurochem 109: 766-775.

Stam R (2007). PTSD and stress sensitisation: a tale of brain and body Part 2: animal models. Neurosci Biobehav Rev 31: 558-584.

Stewart LP, White PM (2008). Sensory filtering phenomenology in PTSD. Depress Anxiety 25: 38-45.

Stinson FS, Grant BF, Dawson DA, Ruan WJ, Huang B, Saha T (2005). Comorbidity between DSM-IV alcohol and specific drug use disorders in the United States: results from the National Epidemiologic Survey on Alcohol and Related Conditions. Drug Alcohol Depend 80: 105-116.

Stinus L, Cador M, Zorrilla EP, Koob GF (2005). Buprenorphine and a CRF1 antagonist block the acquisition of opiate withdrawal-induced conditioned place aversion in rats. Neuropsychopharmacology 30: 90-98.

Threlfell S, Sammut S, Menniti FS, Schmidt CJ, West AR (2009). Inhibition of phosphodiesterase $10 \mathrm{~A}$ increases the responsiveness of striatal projection neurons to cortical stimulation. J Pharmacol Exp Ther 328: 785-795.

Tolkamp BJ, Kyriazakis II (1999). To split behaviour into bouts, log-transform the intervals. Anim Behav 57: 807-817.

Valdez GR, Roberts AJ, Chan K, Davis H, Brennan M, Zorrilla EP et al (2002). Increased ethanol self-administration and anxietylike behavior during acute ethanol withdrawal and protracted abstinence: regulation by corticotropin-releasing factor. Alcohol Clin Exp Res 26: 1494-1501.

Valdez GR, Zorrilla EP, Rivier J, Vale WW, Koob GF (2003). Locomotor suppressive and anxiolytic-like effects of urocortin 3, a highly selective type 2 corticotropin-releasing factor agonist. Brain Res 980: 206-212.

Vendruscolo LF, Barbier E, Schlosburg JE, Misra KK, Whitfield TW Jr., Logrip ML et al (2012). Corticosteroid-dependent plasticity mediates compulsive alcohol drinking in rats. J Neurosci 32: 7563-7571.

Weber M, Breier M, Ko D, Thangaraj N, Marzan DE, Swerdlow NR (2009). Evaluating the antipsychotic profile of the preferential PDE10A inhibitor, papaverine. Psychopharmacology (Berl) 203: 723-735.

Wen RT, Zhang M, Qin WJ, Liu Q, Wang WP, Lawrence AJ et al (2012). The phosphodiesterase-4 (PDE4) inhibitor rolipram decreases ethanol seeking and consumption in alcohol-preferring fawn-hooded rats. Alcohol Clin Exp Res 36: 2157-2167.

West AR, Grace AA (2004). The nitric oxide-guanylyl cyclase signaling pathway modulates membrane activity States and electrophysiological properties of striatal medium spiny neurons recorded in vivo. J Neurosci 24: 1924-1935.

Zhao Y, Weiss F, Zorrilla EP (2007). Remission and resurgence of anxiety-like behavior across protracted withdrawal stages in ethanol-dependent rats. Alcohol Clin Exp Res 31: 1505-1515.

Supplementary Information accompanies the paper on the Neuropsychopharmacology website (http://www.nature.com/npp) 